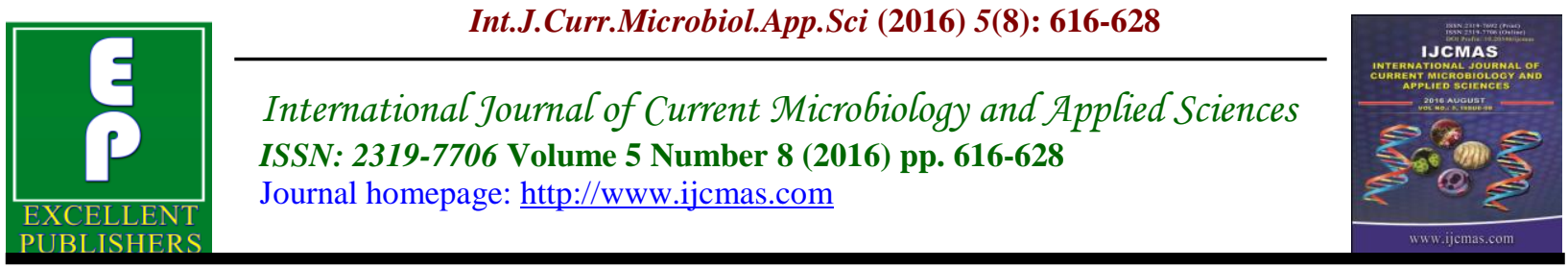

Original Research Article

http://dx.doi.org/10.20546/ijcmas.2016.508.069

\title{
Bioconversion of Disposed Marine Waste into Lipase Enzyme by Streptomyces fungicidicus RPBS-A4
}

\author{
A. Rajanikanth ${ }^{1}$ and T. Damodharam ${ }^{2 *}$ \\ ${ }^{1}$ Department of Biotechnology, Sri Venkateswara University, Tirupati, A.P, India \\ ${ }^{2}$ Department of Environmental sciences, Sri Venkateswara University, Tirupati, A.P, India \\ *Corresponding author
}

A B S T R A C T

Keywords

Marine waste, growth media, lipase production, Streptomyces fungicidicus RPBS-A4.

Article Info

Accepted:

23 July 2016

Available Online:

10 August 2016
Extracellular lipase production by Streptomyces fungicidicus RPBS-A4, previously isolated from the Bay of Bengal has been investigated in submerged fermentation using different proportions of disposed marine wastes such as fish, shrimp and crab as nitrogen source. Among the tested, shrimp waste supported the maximum lipase production. The effect of carbon sources on lipase production revealed that lactose aided the higher lipase production than any other tested carbon source and a concentration of $1.5 \%$ lactose registered as optimum to enhance the lipase production. Among the nitrogen sources tested, lipase production was high in peptone added medium when compared to other nitrogen sources, and its optimum concentration recorded was $1.5 \%$. Partial characterization of crude enzyme revealed that $\mathrm{pH} 9.0$ and $45^{\circ} \mathrm{C}$ temperature were optimum for maximum lipase activity.

\section{Introduction}

Lipases, (triacylglycerol acyl hydrolases, EC 3.1.1.3), are natural catalysts of the hydrolysis of triacylglycerols into di- and monoacylglycerols, fatty acids and glycerol at an oil-water interface, a phenomenon known as interfacial activation (Schmidt et al., 1998). However, under certain conditions, they are also able to catalyze synthetic reactions (Carvalho et al., 2006). The most reported of the reactions carried out by these enzymes are hydrolysis, acidolysis, alcoholysis, aminolysis, esterification and inter-esterification (Saxena et al., 2003). Currently, lipases are a popular choice as a biocatalyst because they can be applied to chemo, regio and enantio selective hydrolyses and also in the syntheses of a broad range of compounds (Jaeger and Eggert, 2002). These enzymes are considered to have great potential as biocatalysts in numerous industrial processes, such as the synthesis of food ingredients (Macedo et al., 2003), their use as additives to detergents (Liu et al., 2009) and to obtain enantiopure drugs and other refined products (Wang et al., 2009). In the chemical industry, they are used for the production of surfactants and detergents, to resolve the racemic mixtures and for the treatment of residues that are rich in oils and 
fats. In the health sector they are used in medicines, diagnostics, cosmetics and antibiotics (Hasan et al., 2006). In the food industry, lipases are used to synthesize emulsifiers such as mono-and diglycerides (Kittikun et al., 2008) and for the production of lipids with high levels of polyunsaturated fatty acids (Reshma et al., 2008). They are also used for the development of flavors (Salah et al., 2007), the maturation of cheese (Dupuis et al., 1993) and sausage meat, among others. Furthermore, lipases have an important application in the field of bioenergy, particularly for the production of biodiesel (Park et al., 2006), which is an expanding sector, given the worldwide concern with the use of renewable energy.

The marine industry generates nearly 50 $60 \%$ of the total weight of fish as waste contains enormous amount of protein (35$50 \%)$ and chitin (15-25\% of dry weight) which are considered as major environmental pollutants due to its uncontrolled dumping (Islam et al., 2004). Production cost of lipase is strongly influenced by expensive medium components like nitrogen, carbon sources such as fatty acids, triglycerides and sugars or complex polysaccharides like glycogen and surfactants. Bioconversion of these disposed fish waste materials has been proposed to be a safer waste treatment option that will solve environmental problems, but also decrease to a large extent the production costs of using microbial enzymes (Liu et al., 2003). Interestingly, fish wastes provide an excellent source for microbial growth, which can be exploited in producing various metabolites (lysine, enzymes, etc.) (Coello et al., 2000; Vazquez et al., 2006, 2008).

Most of the marine actinomycetes are exploited for production of antibiotics but the studies on novel enzyme production from marine actinomycetes is still in infant stage (Bull et al., 2000). Only about 2.0 per cent of the world's microorganisms have been tested as enzyme sources. Streptomyces are the most important industrial microorganisms because of their capacity to produce numerous bioactive molecules, particularly antibiotics and enzymes (Lam, 2006).However many studies were made on production and purification of lipase, no attempt has been made on lipase from marine actinomycetes through bioconversion of marine wastes. Hence in the present study, an attempt was made on production and characterization of lipase from Streptomyces fungicidicus RPBS-A4 by utilization of marine wastes.

\section{Materials and Methods}

\section{Growth Curve for Streptomyces fungicidicus RPBS-A4}

A set of ten $100 \mathrm{ml}$ conical flasks containing $20 \mathrm{ml}$ of starch casein broth were inoculated with Streptomyces fungicidicus RPBS-A4. All the flasks were incubated at $30^{\circ} \mathrm{C}$ and $120 \mathrm{rpm}$ on orbital shaker. One flask was harvested everyday till the tenth day. The biomass was separated from the nutrient medium by centrifugation and washed with distilled water. The biomass was transferred on a filter paper and kept for drying at $55^{\circ} \mathrm{C}$. The dry weight was determined after 24 hrs.

\section{Time Scale Analysis of Streptomyces fungicidicus RPBS-A4}

Time scale analysis was performed in order to determine the fermentation period required for maximum production of lipase. The fermentations were carried out using production medium (Bindiya and Ramana, 2012) supplemented with $1 \%$ olive oil at $30^{\circ} \mathrm{C}$ for $168 \mathrm{hrs}$. Samples were withdrawn every $24 \mathrm{hrs}$ and extracted. The extract was 
assayed for lipase activity (Jensen, 1983; Chandan and Sahani, 1964).

\section{Preparation of marine waste based media}

Marine wastes such as fish, shrimp and crab were collected from disposed sites in Vadarevu near Chirala coast of Andhra Pradesh (India). Five kg of each waste were packed in separate insulated polythene bags and stored at $-20^{\circ} \mathrm{C}$ until use. The disposed waste included heads, viscera, shells and tails. The waste collected were minced by a mixer grinder, mixed with water $(500 \mathrm{~g} / \mathrm{l})$ and heated at $100^{\circ} \mathrm{C}$ for $20 \mathrm{~min}$. After heat pre-treatment, insoluble material was removed by centrifugation $(9390 \mathrm{~g}$ for 10 min) and the supernatant was stored at $4^{\circ} \mathrm{C}$ until use. Supernatants supplemented with different proportions $(0 \%, 25 \%, 50 \%$ and $75 \%)$ of standard medium (SM) were used as media for bacterial growth. The SM was composed of $17 \mathrm{~g} / 1$ casein peptone, $5 \mathrm{~g} / \mathrm{l}$ yeast extract and $2.5 \mathrm{~g} / \mathrm{l}$ glucose, $\mathrm{pH} 7.4$ (Ben Rebah et al., 2008).

Comparison of enzyme production in different media combinations

The marine isolate Streptomyces fungicidicus RPBS-A4 was grown in 3 different media combinations (fish, shrimp and crab waste) to test best growth supporting media and best enzyme producing media. The media were prepared in $100 \mathrm{ml}$ conical flasks contained $50 \mathrm{ml}$ of supernatant derived from marine waste (fish, Shrimp and crab) supplemented with different proportions $(0 \%, 25 \%, 50 \%$ and $75 \%$ ) of standard medium (SM) and $\mathrm{pH}$ was adjusted to 7.0.The flasks were inoculated with $8 \mathrm{~mm}$ disc of inoculum grown on starch casein agar medium for $72 \mathrm{hrs}$. The flasks were incubated at $30^{\circ} \mathrm{C}$ for $96 \mathrm{hrs}$ at 120 rpm.The crude enzyme was extracted at regular time intervals and lipase activity was determined titrimetrically. The extent of growth supported by all the above stated media were also examined because the production of lipase is directly related to growth of organism. The biomass was separated from the medium by centrifugation and washed with distilled water. The biomass was transferred on a filter paper and kept for drying at $55^{\circ} \mathrm{C}$. The dry weight was determined after $24 \mathrm{hrs}$.

\section{Media Optimization for Lipase Production}

Growth conditions and media composition were optimized in separate experiments.

\section{Effect of inoculum size on lipase production}

The isolate Streptomyces fungicidicus RPBS-A4 was inoculated on shrimp waste based medium, as this medium gives relatively fast growth and enzyme activity. Submerged fermentations were carried out by inoculating cutting discs of 5, 6, 7, 8 and $10 \mathrm{~mm}$ diameters in different sets. Fermentation's were carried out at $30^{\circ} \mathrm{C}$ for $96 \mathrm{hrs}$. Samples were withdrawn after $96 \mathrm{hrs}$ and centrifuged; the supernatant collected was assayed for lipase activity and the dry weight was also determined.

\section{Effect of Carbon sources on lipase production combined with substrate}

For the identification of suitable carbon source for lipase production, different carbon sources such as glucose, lactose, sucrose, maltose, groundnut oil, neem oil, coconut oil and palm oil were tested individually at the level of $0.5 \%$. Subsequently, the maximum lipase producing carbon source was further optimized by varying its concentrations such as $0.25 \%, 0.5 \%, 0.75 \%, 1.0 \%, 1.25 \% 1.5 \%$ and $1.75 \%$ in the production medium. 
Effect of Nitrogen sources on lipase production combined with substrate

The effect of nitrogen sources on lipase production was tested by adding different nitrogen sources such as ammonium sulphate, ammonium carbonate, peptone, tryptone, beef extract and yeast extract. After screening the maximum lipase yielding substrate, it was further optimized by varying concentrations $(0.5 \%, 1.0 \%$, $1.5 \%, 2.0 \%, 2.5 \%, 3.0 \%, 3.5 \%$, and $4.0 \%$ ).

\section{Effect of incubation temperature on lipase production}

To determine the effect of temperature on enzyme production, fermentation was carried out at different incubation temperatures ranging from $20^{\circ} \mathrm{C}$ to $55^{\circ} \mathrm{C}$. The samples were withdrawn after $96 \mathrm{hrs}$ and the extracts were assayed for lipase activity.

\section{Effect of $p^{\mathrm{H}}$ on Lipase Activity}

To determine the optimum initial medium $\mathrm{p}^{\mathrm{H}}$ for actinomycetes growth and enzyme production, the production medium $\mathrm{p}^{\mathrm{H}}$ was adjusted from 4.0 to 11.0 using buffering agents $(0.1 \mathrm{M} / \mathrm{L})$, flasks cultured in a incubator-shaker $(120 \mathrm{rpm})$ at $40^{\circ} \mathrm{C}$ and crude enzyme extract was prepared and lipase activity determined.

\section{Effect of agitation speed on Lipase Activity}

To determine the optimal agitation speed for peak enzyme activity, the Streptomyces fungicidicus RPBS-A4 was cultured in an orbital shaking incubator at $40^{\circ} \mathrm{C}$ at varying agitation speed from $60-140 \mathrm{rpm}$. The fermentation process was terminated after $96 \mathrm{hrs}$ and crude enzyme extract was prepared and lipase activity determined.

\section{Results and Discussion}

\section{Growth Curve for Streptomyces fungicidicus RPBS-A4}

The appearance of biomass in the medium started after $24 \mathrm{hrs}$ and increased successively. The growth of Streptomyces fungicidicus RPBS-A4 appeared in the form of small beads in clear transparent medium which is a characteristic feature of Streptomycetes (Williams et al., 1989). The number and size of beads increased as the incubation time increased. The biomass showed a progressive increase till $6^{\text {th }}$ day of incubation but later on the growth was not much. The organism seems to enter the stationary stage after $6^{\text {th }}$ day of incubation. The growth of the isolate is reported in the form of dry weight and graphically presented in Figure.1.

\section{Time Scale Analysis for Streptomyces fungicidicus RPBS-A4}

Production was terminated in a set of flasks after every $24 \mathrm{hrs}$ and the broth was harvested to determine the amount of enzyme produced. The accumulation of enzyme increased till $96 \mathrm{hrs}$ of incubation. Further incubation did not support the increase in productivity of lipase. As the number of bacterial cells goes on increasing the number of enzyme molecules shall increase, therefore high biomass accumulation will result in good enzyme yield. The production of lipase is reported by Vishnupriya et al., (2010) in 24 hrs, Aly et al., (2012) observed the production in 72 hrs and sathya priya et al., (2012) in $96 \mathrm{hrs}$ by Streptomycetes. Maximum accumulation of enzyme in our case was observed in 96 hrs of incubation as also reported by Selvam et al., (2013) for extracellular production by Streptomyces variabilis. Further incubation resulted in loss of enzyme activity. Aysel et 
al., (2014) reported maximum production in $120 \mathrm{hrs}$. The decrease of the enzyme activity during the stationary phase may be explained by the detrimental effects of acidic $\mathrm{pH}$ or some by-products formed in the medium. Presence of proteases may also breakdown the enzyme present in the medium. The lipase activity during seven days period is graphically depicted in Figure. 2.

\section{Selection of Medium Combination}

One problem regarding enzyme production on a large scale is the production cost. A possible alternative for reduction in production cost will come about with the preparation of medium with low cost nitrogen sources. Viewing this, in the present study, an attempt has been made to reduce the production cost using a cheap nitrogen source (marine wastes). Various media combinations were tried for the production of lipase. All the media combinations checked were giving varying enzyme yield and different biomass accumulation. Among all nonsupplemented samples tested as growth media, only supernatants derived from shrimp and fish waste based media showed highest enzyme activity. Interestingly, shrimp waste based medium gave the highest growth yield $(24.85 \mathrm{mg} / \mathrm{ml})$ and exhibited the maximum lipase activity (12.91 U/ ml). In this case, growth yield and lipase activity values exceeded those obtained with the standard medium (SM) $(18.23 \mathrm{mg} / \mathrm{ml}$ and $10.83 \mathrm{U} /$ $\mathrm{ml})$.The supplementation of supernatants with various proportions of SM influenced the growth and lipase activity. In all experiments, the maximum growth was obtained upon adding 75\% SM and the highest growth was obtained for shrimp waste based medium. These results find support with the previous report of Ben Rebah et al., (2008) on lipase production by
Staphylococcus xylosus. They inferred that shrimp waste induce maximum lipase production than other fish wastes. This study also supports the previous findings of Ellouz et al., (2003) and Souissi et al., (2008) on the possible use of fish wastes as nitrogen source for bacterial growth and protease production.

All these media combinations were also checked for stimulating the growth of Streptomyces fungicidicus RPBS-A4. The maximum biomass was produced in shrimp waste based media supplemented with $75 \%$ standard medium. This medium also stimulated high enzyme production but lesser than non supplemented shrimp waste based media. The results of above comparison are graphically represented in Figure.3.

\section{Effect of Inoculum Size on production of Lipase}

The optimisation of fermentation process for industrial application also requires suitable medium for inoculum development. The time required for growth of inoculum should be as less as possible. This can be achieved by selection of a medium which supports fast growth of the organism and also initializes the machinery for the formation of desired product (lipase) in the organism. Starch casein medium is reported to induce lipase production as well as growth of Streptomycetes (Srilekha Mishra and Nibha Gupta, 2014). The inoculation of Streptomyces fungicidicus RPBS-A4 was done by cutting discs of varying sizes, 5, 6, 7, 8 and $10 \mathrm{~mm}$ diameter with the help of a cup borer. The enzyme production was measured for all the flasks. The enzyme yield was increased in the flasks on increasing the inoculum size. The increase in all the parameters was progressive from 5 $\mathrm{mm}$ disc containing flask to $8 \mathrm{~mm}$ disc 
containing flask, but there was no remarkable increase beyond this. The optimisation of industrial processes is based on utilizing minimum resources and getting maximum outputs therefore the marginal increase beyond $8 \mathrm{~mm}$ diameter is not considered significant and $8 \mathrm{~mm}$ disc is picked up as the optimum size of inoculum. The graphical representation of effect of varying inoculum size is shown in Figure. 4 for lipase production and growth response in terms of biomass accumulated.

\section{Effect of carbon sources on the production of lipase}

Carbon is a major component of the cell and the rate at which a carbon source is metabolized can often influence the formation of biomass or production of metabolites Stanbury et al., (1997). In the present study, 8 different carbon sources, glucose, maltose, lactose, sucrose, groundnut oil, neem oil, coconut oil and palm oil were tried to obtain suitable and low cost carbon source for maximum lipase production. Among different carbon sources tried, lactose gave maximum yield (14.16 $\mathrm{U} / \mathrm{ml}$ ) in the media followed by neem oil (10.83 U/ml). Lactose is also reported as an inducer for the enzyme produced by Streptomyces variabilis NGP3 Selvam et al., (2013). The results of the effect of carbon sources checked in shrimp waste based medium are presented in Figure.5.

Increasing concentrations of lactose also increased the enzyme productivity but till a certain limit beyond which there was no substantial increase. There was an increase in the productivity of lipase from $5.83 \mathrm{U} / \mathrm{ml}$ in $0.25 \mathrm{~g} / 100 \mathrm{ml}$ of lactose to $15.41 \mathrm{U} / \mathrm{ml}$ of enzyme in the fermented broth containing $1.5 \%$ of lactose concentration but further increase did not affect the production. This must be due to the highest lactose concentration reached which the organism can bear. Lactose is reported to give high yields of lipase by earlier researchers also. The results of quantitative effect of lactose are shown in Figure. 6.

\section{Effect of nitrogen sources on the production of lipase}

Nitrogen sources including organic and inorganic sources play an important role in the synthesis of enzymes. Organic nitrogen sources can supply many cell growth factors and amino acids, which are needed for cell metabolism and enzyme synthesis. In general, microorganisms afford high yields of lipase when an organic form of nitrogen is used. The inorganic nitrogen sources showed an inhibitory effect on lipase production (Sarkar et al., 1998). In the present study among six different nitrogen sources, peptone gave maximum yield $(14.58 \mathrm{U} / \mathrm{ml})$. The results of the effect of nitrogen sources checked in media are presented in Figure.7. The nitrogen source peptone favored the lipase production in the case of Aspergillus. sp Cihangir and Sarikaya, (2004), Staphylococcus sp. Lp12 pogaku et al., (2010).

All the nitrogen sources tried peptone was found to be the best among them. Therefore its quantitative effect on lipase production was studied. Production of enzyme increased from $11.66 \mathrm{U} / \mathrm{ml}$ to $15.83 \mathrm{U} / \mathrm{ml}$ in the medium with increase in peptone concentration from $0.5 \mathrm{~g} / 100 \mathrm{ml}$ to 1.5 $\mathrm{g} / 100 \mathrm{ml}$ but further increase substantially decreased the production. The literature survey shows that nitrogen content in the media used for the production of lipase ranges from $0.3 \%$ to $3 \%$ and our results are also falling in the same range (Alok kumar et al., 2013). The results are shown in Figure.8. 
Effect of Temperature on production of Lipase

The production of lipase was found to be maximum at $37^{\circ} \mathrm{C}$ as also reported by Aly et al., (2012) for lipase production by Streptomyces exfoliates. Sirisha et al., (2010) observed maximum lipase production from a non filamentous organism Staphylococcus at $36^{\circ} \mathrm{C}$. The results are presented in Figure. 9. The temperature optima were determined and highest enzyme production was observed at $40^{\circ} \mathrm{C}$. Many of the earlier researchers also have reported the production of enzyme between $30^{\circ} \mathrm{C}$ to $35^{\circ} \mathrm{C}$ Selvem et al., (2013). Thermophilic organisms are also reported to produce lipase in considerable concentrations having high optimum temperature of $55^{\circ} \mathrm{C}$ as optimum for lipase production from Streptomycetes isolated from marine sediments Sathyapriya et al., (2012).

\section{Effect of $p^{\mathrm{H}}$ on production of Lipase}

A broad range of $\mathrm{p}^{\mathrm{H}}$ was tested for optimisation of lipase production by Streptomyces fungicidicus RPBS-A4. There was no production as well as growth observed at $\mathrm{p}^{\mathrm{H}} 4.0$ and 5.0 but the flasks having $\mathrm{p}^{\mathrm{H}} 8.0$ and 9.0 exhibited substantial production of lipase. The production was further reduced on $\mathrm{p}^{\mathrm{H}} 10.0$ and 11.0 but the overall picture exhibited by the organism indicates the preference of alkaline $\mathrm{p}^{\mathrm{H}}$ range with maximum at $\mathrm{p}^{\mathrm{H}}$ 9.0. There are earlier reports on production of lipase at alkaline $\mathrm{p}^{\mathrm{H}}$, Aly et al., (2012) exhibited maximum lipase production at $\mathrm{p}^{\mathrm{H}}$ 6.0, Nadia et al., (2001) observed at $\mathrm{p}^{\mathrm{H}} 7.0$ and Sathyapriya et al., (2012) observed at $\mathrm{p}^{\mathrm{H}}$ 9.0. Selvam et al., (2013) also observed Streptomyces variabilis producing lipase between $\mathrm{p}^{\mathrm{H}} 9.0$ to 9.5. The results are presented in Figure.10.

\section{Effect of Agitation Rate on production of Lipase}

The production of lipase from Streptomyces fungicidicus RPBS-A4 was studied on a range of agitation rates. The highest yield of lipase was observed at $120 \mathrm{rpm}$ on shrimp waste based medium. The results are presented in Figure. 11. Lipase production in the flasks incubated at 60 and $80 \mathrm{rpm}$ was exhibited very poor yield but those incubated at 120 and $140 \mathrm{rpm}$ was ample enough. Selvam et al., (2013) have reported optimum lipase production at $120 \mathrm{rpm}$.

Fig.1 Growth curve of Streptomyces fungicidicus RPBS-A4.

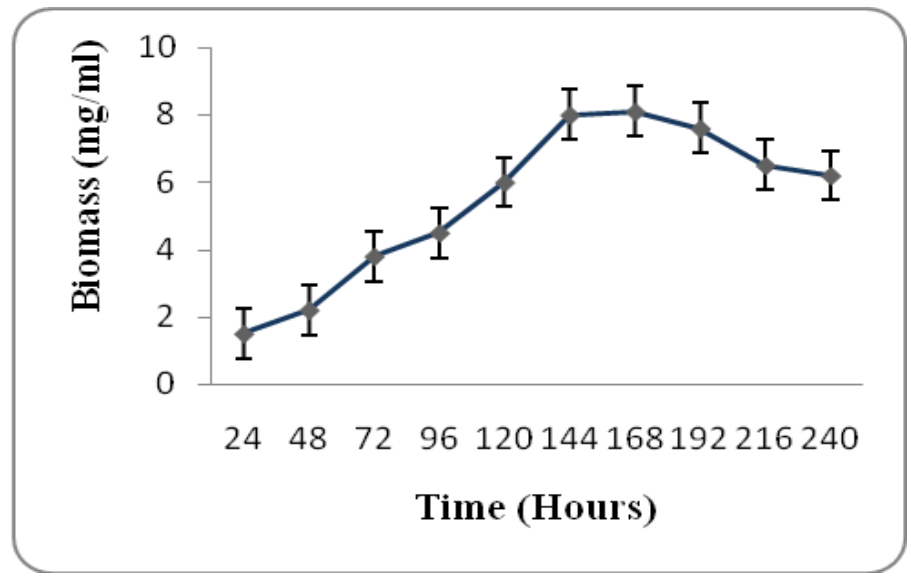


Fig.2 Production of Extracellular lipase at different time intervals by Streptomyces fungicidicus RPBS-A4.

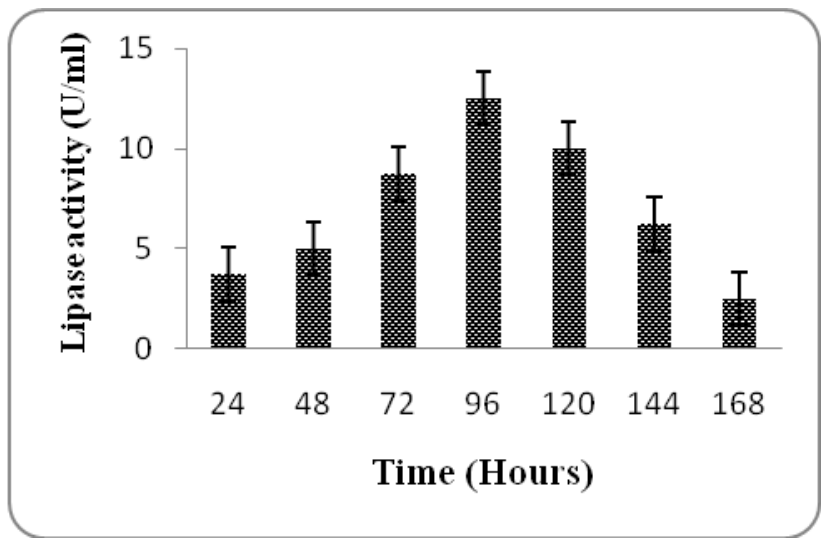

Fig.3 Effect of different media combinations on lipase production and biomass yield

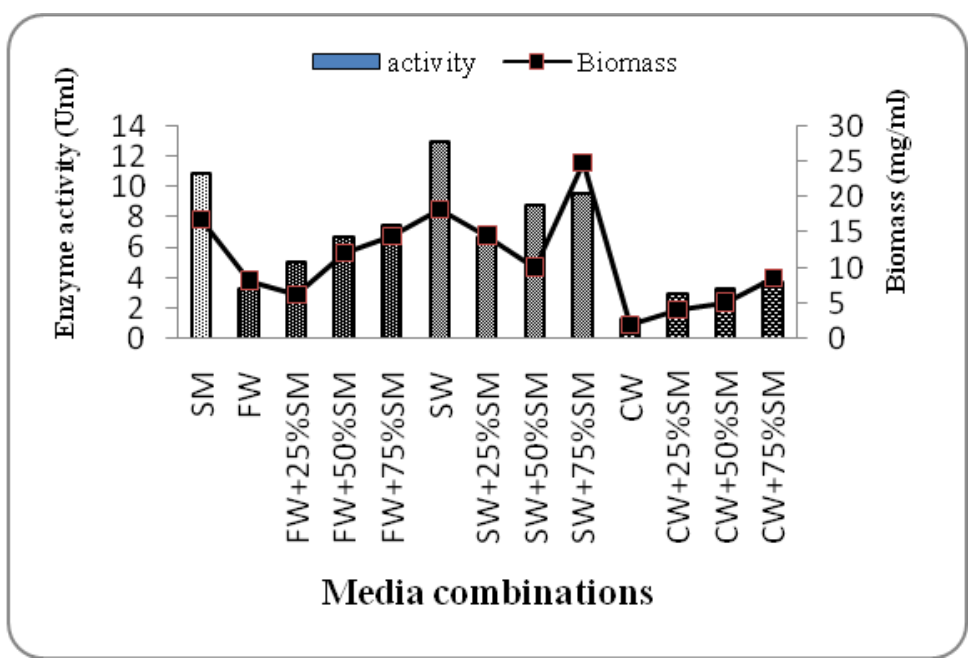

Fig.4 Effect of inoculum size on lipase production

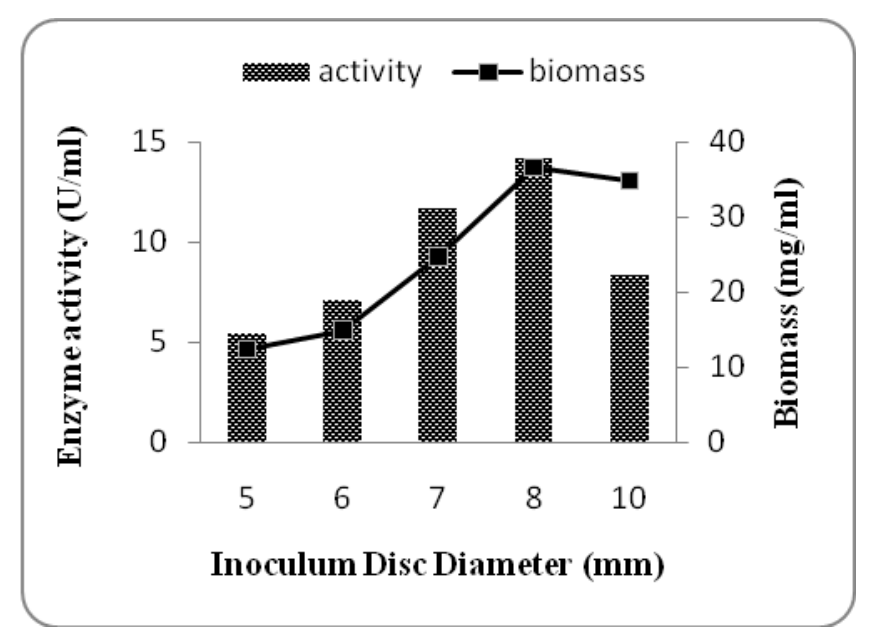


Fig.5 Effect of carbon sources on lipase production

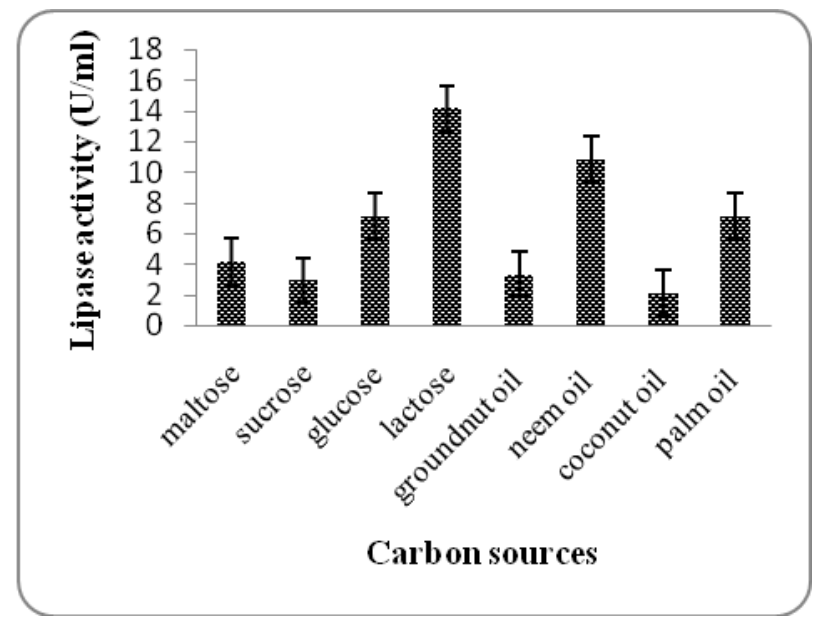

Fig.6 Effect of concentration of carbon source on lipase production

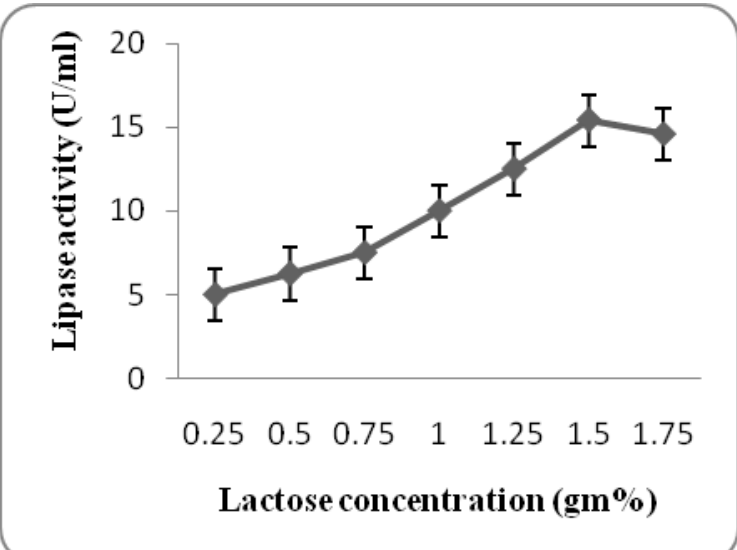

Fig.7 Effect of nitrogen sources on lipase production

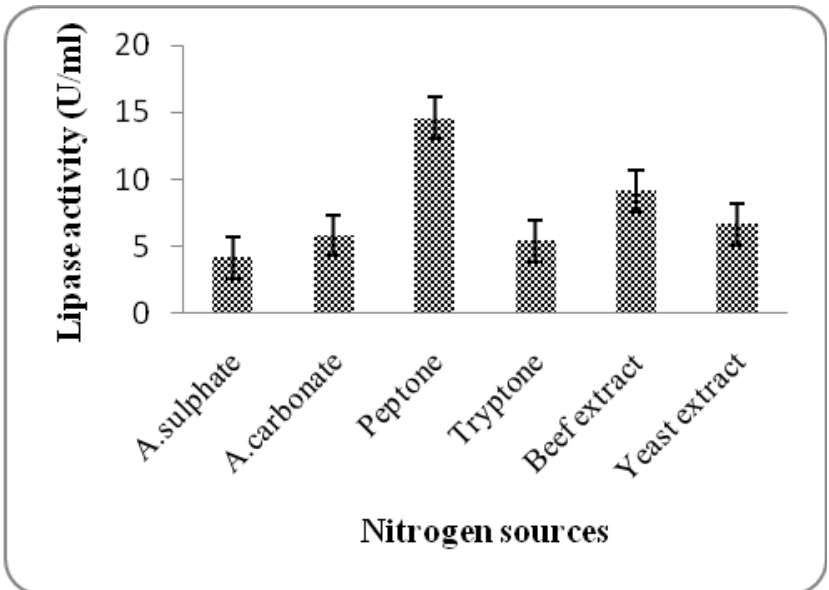


Fig.8 Effect of concentration of nitrogen source on lipase production

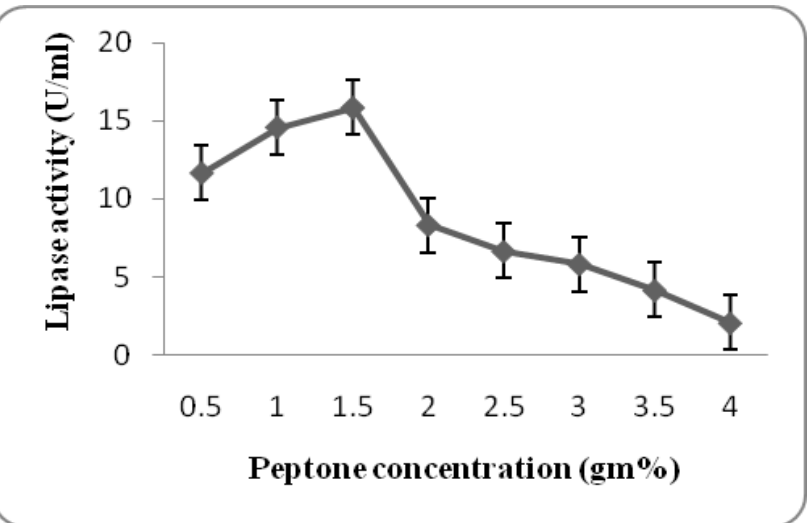

Fig.9 Effect of temperature on lipase production

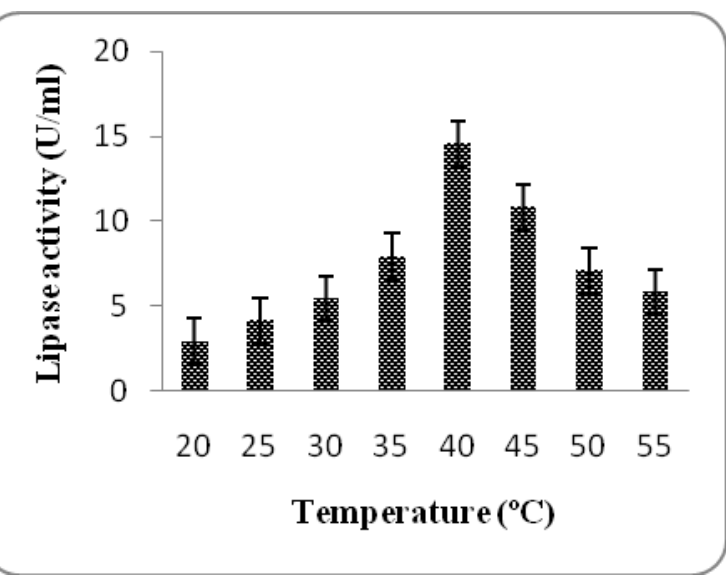

Fig.10 Effect of pH on lipase production

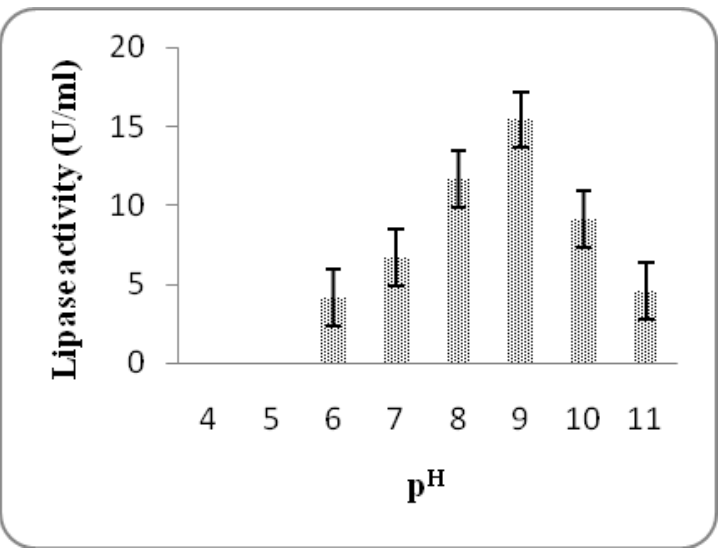


Fig.11 Effect of agitation rate on lipase production

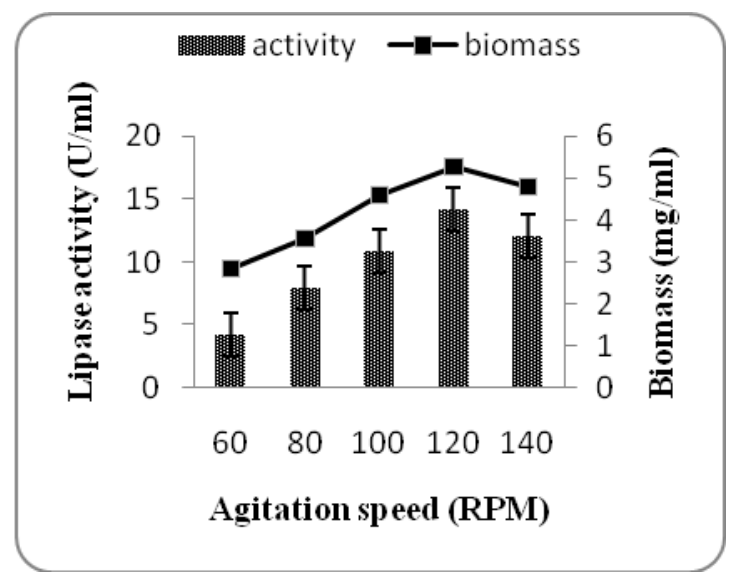

In conclusion, the biomass increase was observed continuously for 10 days but there was a progressive increase till 6th day which is associated with enzyme accumulation, this also indicates that the organism moves to its stationary phase where the increase in enzyme accumulation ceases. The decrease in the enzyme level in later days must be due to the proteolytic activities going on in the medium and decrease in the number of surviving cells in the decline phase of organism's life cycle which can compensate the loss. Time scale analysis showed that maximum activity of enzyme obtained till $96 \mathrm{hrs}$ of incubation. The isolate Streptomyces fungicidicus RPBS-A4 was able to produce lipase on a wide range of carbon and nitrogen sources. The best was lactose among the pure carbon sources and shrimp waste based medium among marine wastes. Presence of peptone exhibited the enhancement in lipase activity and biomass. The scaling up of process requires transition of medium ingredients to crude sources. The crude sources like shrimp waste and fish waste gave good yields which is again beneficial for industrial purposes.

The ingredients we found to be beneficial are lactose in $1.5 \%$ concentration, peptone in $1.5 \%$ concentration. The temperature optima were determined and highest enzyme production was observed at $40^{\circ} \mathrm{C}$. Production of lipase at alkaline $\mathrm{p}^{\mathrm{H}} 9.0$ exhibited maximum lipase production. The production of lipase was studied on a range of agitation rates. The highest yield of lipase was observed at $120 \mathrm{rpm}$ on shrimp waste based medium. The results indicate that shrimp waste can be used as economically available marine wastes for industrial production process. Use of marine wastes for industrial production of metabolites not only reduces the production cost but also solves the problem of disposal of tonnes of marine wastes produced every year in a fish supplying country like India.

\section{References}

Alok Kumar, Hari Ram, Lebin Thomas and Ved Pal Singh. 2013. Selection of Culture Media and Optimization of Media Composition for Extracellular Production of Lipase by Acinetobacter sp. AH-19. Soc. Plant Res., Vol. 26: 175-182.

Aly, M.M.S., Tork, S.M. Al-Garni. and Nawar, L. 2012. Production of lipase from genetically improved Streptomyces exfoliates LP10 isolated from oil contaminated soil. African $J$. Microbiol. Res., 6(6): 1125-1137.

Liu, B.L., Kao, P.M., Tzeng, Y.M. and Feng, K.C. 2003. A solvent stable 
metalloprotease produced by Bacillus sp. TKU004 and its application in the deproteinization of squid pen for $b-$ chitin preparation, Enzyme and Microbial. Technol., 33: 410-415.

Ben Rebah, F., Frikha, F., Kammoun. W., Belbahri, L., Gargouri, Y. and Miled, N. 2008. Culture of Staphylococcus xylosus in fish processing by-productbased media for lipase production. Letters in Appl. Microbiol., 47: 549554.

Bindiya, P. and Ramana, R. 2012. Optimization of lipase production from an indigenously isolated marine Aspergillus sydowii of Bay of Bengal. J. Biochem. Technol., 3(5): S203-S211.

Bull, A.T., Alan, C.W. and Michael, G. 2000. Search and discovery strategies for biotechnol.: the paradigm shift. Microbiol. Mol. Biol. Rev., 64: 573606.

Carvalho, P.O., Contesini, F.J. and Ikegaki, M.2006. Brazilian J. Microbiol., 37: 329-337.

Chandan, R.C., and Sahani, K.M. 1964 Milk lipases. A review. J. Dairy Sci., 47(5), 471-480.

Cihangir, N., and Sarikaya, E. 2004. Investigation of lipase production by a new isolate of Aspergillus .sp. World $J$. Microbiol. Biotechnol., 20(2), 193-197.

Coello, N., Brito, L. and Nonus, M. 2000. Biosynthesis of L-lysine by Corynebacterium glutamicum grown on fish silage. Bioresource Technol., 73:221-225.

Dupuis, C., Corre, C. and Boyaval, P. 1993. Lipase and esterase activities of Propionibactenium freudenreichii subsp. freudenreichii. Applied Environ. Microbiol., 59 (12): 4004-4009.

Ellouz, Y.T., Ghorbel, B., Souissi, N., Kammoun, S., and Nasri, M. 2003. World J. Microbiol. \& Biotechnol., 19, 41-45.

Hasan, F., Shah, A.A. and Hameed, A. 2006. Industrial applications of microbial lipases, Enzyme Microbial Technol.,
39(2): 235-251.

Jaeger, K.E. and Eggert, T. 2002. Current Opinion in Biotechnol., 13: 390-397.

Jensen, R.G. 1983. Detection and determination of lipase (acylglycerol hydrolase) activity from various sources. Lipids, 18: 650-657.

Kittikun, A.H., Kaewthong, W. and Cheirsilp, B. 2008. Continuous production of monoacylglycerols from palmolein in packed bed reactor with immobilized lipase PS. Biochem Eng. J., 40: 116120.

Lam, K.L. 2006. Discovery of novel metabolites from marine actinomycetes. Curr. Opinion in Microbiol., 9: 241-255.

Liu, R., Jiang, X., Mou, H., Guan, H., Wang, H. and Li, X. 2009. Biochem. Eng. J., 46: 265-270.

Islam, M.S., Khan, S. And Tanaka, M. 2004. Waste loading in shrimp and fish processing effluents: potential source of hazards to the coastal and near shore environments, Marine Pollutants Bull., 49: 103-110.

Macedo, G.A., Lozano, M.M.S. and Pastore, G.M. 2003. Electron. J. Biotechnol., 6: $72-75$.

Nadia, H. and Abd El-Nasser. Efficient production, purification and partial characterization of an alkaline lipase from grey Streptomyces.

Park, E.Y., Sato, M. and Kojima, S. 2006. Fatty acid methyl ester production using lipase immobilizing silica particles with different particle sizes and different specific surface areas. Enzyme Microbial Technol., 39: 889896.

Pogaku, P., Suresh, A., Srinivas, P. and Reddy, S.R. 2010. Optimization of lipase production by Staphylococcus sp. Lp12. African J. Biotechnol., 9(6), 882-886.

Sathishkumar, R., Ananthan, G., and Raghunathan, C. 2014. Production and characterization of haloalkaline protease from ascidian-associated 
Virgibacillus halodenitrificans RSKCAS1 using marine wastes, Annals of Microbiol., 13213-014-09878.

Reshma, M.V., Saritha, S.S., Balachandran, C. and Arumughan, C. 2008. Lipase catalyzed interesterification of palm stearin and rice bran oil blends for preparation of zero trans shortening with bioactive phytochemicals. Biores. Technol., 99 (11):5011-5019.

Salah, R.B., Ghamghui, H., Miled, N., Mejdoub, H.and Gargouri, Y. 2007. Production of butyl acetate ester by lipase from novel strain of Rhizopus oryzae. J. Biosci. Bioengi., 103(4): 368-372.

Sarkar, S.B., Sreekanth, B., Kant, S., Banerjee, R., and Bhattacharyya, B. C. 1998. Production and optimization of microbial lipase. Bioprocess Engineering, 19(1), 29-32.

Sathya Priya, B., Stalin, T. and Selvam, K. 2012. Ecofriendly management of mixed coconut oil cake waste for lipase production by marine Streptomyces indiaensis and utilization as detergent additive. Int. J. Water Res. Environ. Engi., Vol. 4(8), pp. 275-280.

Saxena, R.K., Davidson, W.S., Sheron, A. and Giri, B. 2003. Process Biochem., 39: 239-247.

Schmidt, R.D.,Verger, R. and Angew. 1998. Chem. Int. Ed. Engl., 37:1608-1633.

Selvam, K and Vishnupriya, B. 2013. Partial purification of lipase from streptomyces variabilis NGP3 and its application in bioremediation of waste water. Int. J. Pharmaceutical Sci. Res., Vol. 4(11): 4281-4289.

Sirisha, E., Rajasekhar, N. and Narasu, M.L. 2010. Isolation and optimization of lipase producing bacteria from oil contaminated soils. Adv. Biol. Res., 4(5), 249-252.

Souissi, N., Ellouz, Y. T., Bougatef, A., Blibech, M. and Nasri, M. 2008. Microbiol. Res., 163: 473-480.

Srilekha Mishra and Nibha Gupta. 2014. Development of Modified Medium for Enhanced Production of Lipase by Streptomyces Halstedii Strain ST 70 Obtained From Bhitarkanika Mangroves. Int. J. Biotech. Trends and Technol., Volume 7 Issue 1.

Stanbury, P. F., Whitaker, A. and Hall, S. J. 1997. Principles of Fermentation Technol. (2nd Ed.). Aditya Books (P) Ltd., New Delhi.

Vazquez, J.A., Docasal, S.F., Miron, J., Gonzalez, M.P. and Murado, M.A. 2006. Proteases production by two Vibrio species on residuals marine media. J. Industrial Microbiol. Biotechnol., 33: 661-668.

Vazquez, J.A., Docasal, S.F., Prieto, M.A., Gonzalez, M.P. and Murado, M.A. 2008. Growth and metabolic features of lactic acid bacteria in media with hydrolysed fish viscera. An approach to bio-silage of fishing by-products. Biores. Technol., 99: 6246-6257.

Wang, P.Y., Chen, Y.J, Wu, A.C., Lin, Y.S., Kao, M.F., Chen, J.R., Ciou, J.F. and Tsai S.W. 2009. Adv. Synthesis of Catalysis, 351:2333-2341.

\section{How to cite this article:}

Rajanikanth, A., and Damodharam, T. 2016. Bioconversion of Disposed Marine Waste into Lipase Enzyme by Streptomyces fungicidicus RPBS-A4. Int.J.Curr.Microbiol.App.Sci. 5(8): 616-628. doi: http://dx.doi.org/10.20546/ijcmas.2016.508.069 